\title{
Combined prime-boost vaccination against tick-borne encephalitis (TBE) using a recombinant vaccinia virus and a bacterial plasmid both expressing TBE virus non-structural NSI protein SE Aleshin ${ }^{1}$, AV Timofeev ${ }^{1,5}$, MV Khoretonenko1, LG Zakharova ${ }^{2}$, GV Pashvykina2 ${ }^{2}$ JR Stephenson ${ }^{3}$, AM Shneider ${ }^{4}$ and AD Altstein*2
}

\author{
Address: ${ }^{1}$ Chumakov Institute of Poliomyelitis and Viral Encephalitis RAMS, Moscow Region, Russia, ${ }^{2}$ Institute of Gene Biology RAS, Moscow, \\ Russia, ${ }^{3}$ London School of Hygiene and Tropical Medicine, London, UK, ${ }^{4}$ Cure Lab Inc., Stoughton, MA, USA and ${ }^{5}$ Engelhardt Institute of \\ Molecular Biology RAS, Vavilov str. 32, 119991 Moscow, Russia \\ Email: SE Aleshin - aleshins@gmail.com; AV Timofeev - timofeev@com2com.ru; MV Khoretonenko - timofeev@com2com.ru; \\ LG Zakharova - altstein.ad@relcom.ru; GV Pashvykina - altstein.ad@relcom.ru; JR Stephenson - j.stephenson@shtm.ac.uk; \\ AM Shneider - ashneider@curelabvaccines.com; AD Altstein* - altstein.ad@relcom.ru \\ * Corresponding author
}

Published: 02 August 2005

BMC Microbiology 2005, 5:45 doi:10.1186/147I-2180-5-45

This article is available from: http://www.biomedcentral.com/I47I-2/80/5/45

(C) 2005 Aleshin et al; licensee BioMed Central Ltd.

This is an Open Access article distributed under the terms of the Creative Commons Attribution License (http://creativecommons.org/licenses/by/2.0), which permits unrestricted use, distribution, and reproduction in any medium, provided the original work is properly cited.

\begin{abstract}
Background: Heterologous prime-boost immunization protocols using different gene expression systems have proven to be successful tools in protecting against various diseases in experimental animal models. The main reason for using this approach is to exploit the ability of expression cassettes to prime or boost the immune system in different ways during vaccination procedures. The purpose of the project was to study the ability of recombinant vaccinia virus (VV) and bacterial plasmid, both carrying the NSI gene from tick-borne encephalitis (TBE) virus under the control of different promoters, to protect mice against lethal challenge using a heterologous prime-boost vaccination protocol.
\end{abstract}

Results: The heterologous prime-boost vaccination protocol, using a VV recombinant and bacterial plasmid, both containing the NSI TBE virus protein gene under the control of different promoters, achieved a high level of protection in mice against lethal challenge with a highly pathogenic TBE virus strain. No signs of pronounced TBE infection were detected in the surviving animals.

Conclusion: Heterologous prime-boost vaccination protocols using recombinant $\mathrm{VV}$ and bacterial plasmids could be used for the development of flavivirus vaccines.

\section{Background}

Prime-boost immunization protocols using different expression systems have proven to be successful tools in protecting experimental animals against various important human diseases [1] including tuberculosis [2], AIDS [3], and hepatitis $C[4]$. The success of such vaccination schemes depends upon the efficiency of the expression systems, of which, recombinant vaccinia virus(VV) and bacterial plasmid vectors are among the more common systems studied [6-8]. Moreover, it has been shown that when at least one component in a prime-boost vaccination scheme includes a plasmid vector, there is a strong 
Table I: Protection of experimental animals against TBE virus in mice immunized with a vaccinia virus recombinant and a bacterial plasmid, both carrying the gene for the NSI non-structural TBE virus protein

\begin{tabular}{|c|c|c|c|}
\hline Group number & Primary immunization & Booster immunization & $\begin{array}{l}\text { surviving/infected animals (\% of } \\
\text { survivers } \pm \text { SE) }\end{array}$ \\
\hline I & VVW-NSI & pMV45 & $8 / 10(80 \pm 13 \%)$ \\
\hline 2 & VVW-NSI & PMVIO0 & $2 / 10(20 \pm 13 \%)$ \\
\hline 3 & VV WR & pMV45 & $4 / 10(40 \pm 15 \%)$ \\
\hline 4 & VV WR & pMVIO0 & $0 / 10(0 \%)$ \\
\hline 5 & None & None & $0 / 10(0 \%)$ \\
\hline
\end{tabular}

*- Balb/c mice were primed either with vaccinia viruses WR or W-NSI, boosted with bacterial plasmids pMV45 or pMVI00 and challenged intraperitoneally with the TBE virus (Absettarov strain, 100 LD $_{50}$ ) as described in the Materials and Methods section. All the animals were monitored for 3 weeks after challenge with TBE virus. Standard error (SE) of a percent value was determined by the equation: SE = Square root of $\mathrm{p} \times(100-\mathrm{p}) / \mathrm{n}$, where $\mathrm{p}$ is a percent value and $\mathrm{n}$ is a number of animals used. Significance between two percent values (with probability 0.95$)$ : $t=\mathrm{PI}-$ $\mathrm{P} 2 /$ square root of SEI ${ }^{2}+\mathrm{SE} 2^{2} \geq 2.0[14]$.

response from both pathways of the host immune system [8]. There is no unique mechanism to account for the efficiency of prime-boost vaccination protocols, but it is well known that synergy of priming and boosting in the host using different expression vectors evokes high-avidity CD4 and CD8 cells [5]. Consequently, several such vaccination protocols are now in human clinical trials $[1,6]$. Here we present the results of experiments employing the sequential use of recombinant $\mathrm{VV}$ and a bacterial plasmid, both expressing non-structural protein, NS1, of tick borne encephalitis (TBE) virus, in protecting mice against lethal virus infection. It has previously been shown that both expression systems independently can partially protect mice against lethal challenge with the highly pathogenic TBE virus strain but only after repeated revaccinations $[9,10]$. Despite the efficiency of commercially available whole-virion TBE vaccines [11], concerns have been expressed about the development of non-neutralizing anti-envelope antibodies that could enhance the infection [12] if vaccination protocols are not followed, as well as if individuals are subclinically infected with other flaviviruses or immune compromised. The use of another protective TBE virus antigen, such as the NS1 non-structural protein, presented by different expression systems may help to address these concerns in some circumstances $[9,10,13]$.

\section{Results and discussion}

The results that were obtained with different vaccination protocols against TBE are presented in Table 1. The combined vaccination scheme of both vectors without the NS1 gene (VV-WR and pMV100) did not protect mice against lethal challenge ( $0 \%$ of protection). The recombinant vaccinia virus (W-NS1) in combination with the control plasmid pMV100 protected $20 \%$ of challenged mice, whereas $40 \%$ of mice survived that were primed with control vaccinia vector VV-WR and boosted with the NS1 gene expressing plasmid pMV45 (the difference is statistically insignificant). When mice were primed with the recombinant VV W-NS1 and boosted with plasmid pMV45, the level of protection significantly increased $(80 \%)$.

Detection of anti-NS1 and anti-E (envelope protein) antibodies in vaccinated and challenged mice was carried out by radioimmuno precipitation analysis (RIPA). The analysis did not detect anti-NS1 antibodies in the blood of mice after primary vaccination with the recombinant vaccinia virus (W-NS1) (Fig. 1, lanes 5 and 6) but they were detected after booster vaccination with the recombinant plasmid pMV45 (Fig. 1, lanes 7 and 8). Anti-NS1 antibodies were also detected in vaccinated animals after subsequent challenge with the TBE virus (Fig. 2, lanes 7 and 8). However, sera from surviving mice did not contain antibodies against TBE virus E protein, suggesting that pronounced virus infection was not present in vaccinated and challenged animals (Fig. 2, lanes 7 and 8). In separate experiments, neither the W-NS1 recombinant nor the pMV45 plasmid, introduced alone, induced detectable amount of anti-NS1 antibodies in mice (data not shown).)Antibodies against NS1 protein could protect mice against the lethal challenge with homologous flaviviruses including TBE virus $[15,16]$. Involvement of $\mathrm{Th}_{1}$ immune response in protection elicited by the combined vaccination with two recombinant systems used in this study can not be excluded.

These studies are the first to demonstrate that the combined use of well-characterised expression systems employing recombinant vaccinia viruses and bacterial plasmids (DNA vaccination) can protect experimental animals against a lethal flavivirus infection. Both these expression systems could be rapidly deployed to provide simple methods of constructing vaccines against several dangerous emerging diseases that have caused severe 


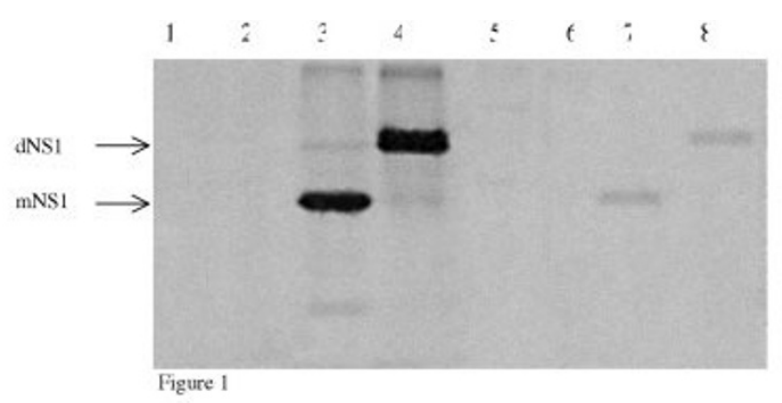

Figure I

Study of mouse sera in RIPA with the TBE virus infected and radioactive labeled SPEV cell extracts. Lanes I and 2 - serum from intact mice; lanes 3 and 4 mouse anti-NSI sera [9]; lanes 5 and 6 - pooled sera of mice vaccinated with the vaccinia virus recombinant (W-NSI); lanes 7 and 8 - pooled sera from mice primed with W-NSI after booster vaccination with pMV45. Odd lanes: samples were boiled before SDS electrophoresis to detect NSI-monomers; even lanes: samples were not boiled before electrophoresis to detect NSI-dimers. The position of monomers $(\mathrm{mNSI})$ and dimers (dNSI) of the NSI protein are marked with arrows.

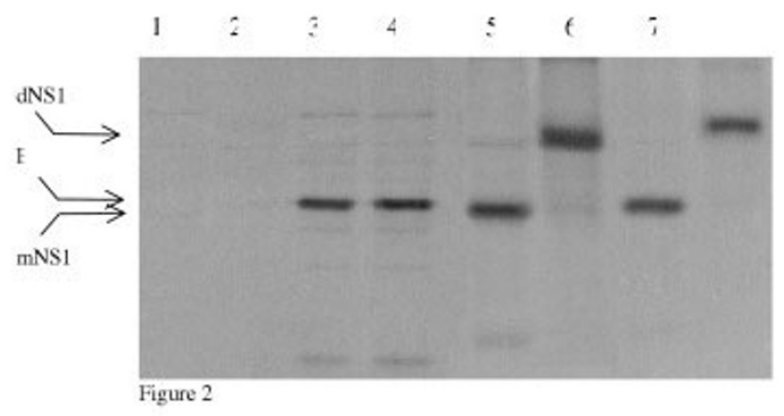

Figure 2

Study of mouse sera in RIPA with the TBE virus infected and radioactive labeled SPEV cell extracts. Lanes I and 2 - serum from intact mice; lanes 3 and $4-$ antiE protein Mab; lanes 5 and 6 - mouse anti-NSI serum [9]; lanes 7 and 8 - pooled sera from mice vaccinated with $W$ NSI and PMV45 which survived after the challenge with the TBE virus. Odd lanes: samples were boiled before SDS electrophoresis; even lanes: samples were not boiled before electrophoresis. The position of E protein, monomers ( $\mathrm{mNSI}$ ) and dimers (dNSI) of the NSI protein are marked with arrows. threats to public health in many different countries during the past few years.

In our experiments we used the poxvirus recombinant based on the WR laboratory strain which replicates better in cell cultures and mice than other strains of $\mathrm{VV}$. Although more convenient for our experiments, this strain could not be used directly for vaccination of humans due to its relatively high virulence. However, it can easily be used to prepare the analogous recombinants on the basis of vaccinal VV strains (Lister, Copenhagen, Praha and others) by inserting the NS1 gene into their tk gene. These strains have been broadly used for immunization against smallpox in the past.

Although vaccination against smallpox was stopped many years ago, it could be reinstated if a bioterrorist attack is thought to be imminent. Indeed, the USA, UK and several other European countries have stockpiled traditional vaccines as a precaution against such an event. However, it could be argued that it is more sensible to vaccinate humans, not with the traditional vaccinal VV strains, but with their recombinants carrying genes encoding protective antigens from other pathogens, inserted into the $\mathrm{VV}$ thymidine kinase ( $t k)$ gene [17]. Despite the fact that VV tk- recombinants have never been used for vaccinations against smallpox in the past, there are many reasons that they could protect against the disease as with the original VV strains: 1) they have the same antigenic structure; 2) a $t k^{-}$recombinant constructed on the basis of the Lister strain that expressed hepatitis B virus HBsAg antigen [18] could efficiently replicate in calf skin, which enabled the production of dermal recombinant vaccine against hepatitis B and to conduct human trials [19]; 3) this recombinant induced a specific reaction in rabbit, calf and human skin and evoked neutralizing antibodies against orthopoxviruses $[19,20]$. Such recombinants would have substantial advantages over traditional VV. Not only would they possess reduced neurovirulence due to destruction of the th gene $[18,21,22]$ (residual neurovirulence of $\mathrm{VV}$ is a main cause of severe postvaccinal complications), but they would also be able to offer protection against smallpox and another pathogen. For instance, VV recombinants expressing protective antigens of TBE virus, including NS1 protein, could be used in TBE endemic regions. In this case, prime-boost vaccination protocols, which include recombinant bacterial plasmids as a booster, could provide protection against TBE without raising concerns that pre-existing immunity to vaccinia virus could reduce the immune response to TBE viral proteins. Such strategies could also help to cut the cost of the vaccination procedure, thus making them attractive public health interventions. 


\section{Conclusion}

A combined prime-boost vaccination protocol, including a VV recombinant and a bacterial plasmid, both containing the NS1 non-structural TBE virus protein gene, gave high levels of protection in mice against lethal challenge with the highly pathogenic TBE virus strain. This primeboost vaccination protocol could be employed in the development of novel flavivirus vaccines for use in TBE endemic areas and in situations where a reintroduction of smallpox may occur.

\section{Methods}

\section{Viruses and plasmids}

The TBE virus strains Absettarov and Sophyin were obtained from the collection of viruses at the Chumakov Institute of Poliomyelitis and Viral Encephalitis RAMS, as mouse brain suspensions with known $\mathrm{LD}_{50}$ titres. The recombinant bacterial plasmid pMV45, carrying the gene for the non-structural TBE virus protein NS1 (Western subtype Neudorfl), under the control of the cytomegalovirus immediate early promoter has been described earlier [13]. Plasmid pMV100, carrying the cytomegalovirus expression cassette without an insert was used as a negative control [13]. Plasmid preparations were performed according to EndoFree Plasmid Mega protocol (QIAGEN Inc., USA). The construction and characterisation of the VV recombinant (W-NS1), expressing the TBE virus nonstructural NS1 protein gene, inserted into the th gene under the control of the synthetic early-late poxvirus promoter has been described previously [10]. The recombinant and the parental vaccinia virus strain (WR strain) were propagated and titrated in the CV1 simian kidney cells.

\section{Animal experiments}

Male Balb/c mice weighing 10-12 g were used. The VV recombinant and the negative control virus were injected intraperitoneally as doses of $10^{7} \mathrm{PFU} /$ mouse. The bacterial plasmids were introduced intramuscularly as $50 \mu \mathrm{g}$ doses per mouse. The interval between vaccinations was 2 weeks. Two weeks after the last vaccination, mice were challenged intraperitoneally with $100 \mathrm{LD}_{50}$ of the highly virulent TBE virus strain Absettarov (Western subtype) and monitored for 3 weeks. Not less then 5 mice from each group were bled before the challenge and their sera were pooled. The survivors from groups vaccinated with W-NS1 and pMV45 were also bled and their sera pooled for analysis. All experiments involving live animals were conducted according to International guidelines on the ethical use of animals.

\section{Analysis by radioimmune precipitation (RIPA)}

Continuous cultures of porcine embryo kidney cells (SPEV) were infected with $1 \mathrm{PFU} / \mathrm{cell}$ of TBE virus (strain Sophyin). Thirty-six hours after infection Earl's 199 medium with $0.1 \%$ of human serum albumin (v/v) was substituted for Earl's salt solution. A ${ }^{14} \mathrm{C}$-labelled amino acid mixture (Amersham, USA) was added at a concentration of $2.5 \mu \mathrm{Ci} / \mathrm{ml}$ and the cell sheets were harvested 12 hours later, lysed in immune precipitation buffer followed by three rounds of freezing and thawing as described previously [23].

The RIPA procedure was carried out for detection of antibodies against TBE virus NS1 and envelope E proteins using Protein A -Sepharose with subsequent electrophoresis of precipitates in $10 \%$ SDS-PAGE and exposure to Xray film as described earlier $[9,23]$. E and NS1 protein monomers migrate closely on $10 \%$ SDS PAGE gel. In order to identify them on a gel, we used the boiled and unboiled variants of samples for electrophoresis. The unboiled samples of NS1 protein contain NS1 dimers. Boiling does not influence the electrophoretic mobility of E protein. Mouse anti-NS1 serum was obtained by vaccination of animals with pMV45 [9]. Monoclonal antibody (Mab) against TBE virus E protein was a kind gift of Dr. A. Kushch (Ivanovsky Institute of Virology RAMS, Moscow, Russia).

\section{Authors' contributions}

AMS and JRS designed the general principles of the project, ADA and AVT were involved in design of experiments and drafting the manuscript and SEA and MVK carried out animal and immunological experiments. LGZ and GVP carried out the microbiological and virological studies and the manuscript was read and approved by all the authors.

\section{Acknowledgements}

This work was partially supported by the Russian Fund for Basic Research (grant N02-04-49757), Cure Lab Inc., USA, and the Wellcome Trust Grant No: 064845. Authors are cordially thankful to the Chumakov State Unitary Enterprise, Russia, for the help in conducting the animal experiments and Dr. G. Thoidis (Boston University, Boston, USA) for the help in editing of the manuscript.

\section{References}

I. Woodland DL: Jump-starting the immune system: primeboosting comes of age. Trends Immunol 2004, 25:98-104.

2. McShane H, Brookes R, Gilbert S, Hill A: Enhanced immunogenicity of CD4 (+) t-cell responses and protective efficacy of a DNA-modified vaccinia virus Ankara prime-boost vaccination regimen for murine tuberculosis. Infect Immun 200I, 69:681-686.

3. Koopman G, Mortier D, Hofman S, Niphuis H, Fagrouch Z, Norley S, Sutter G, Liljestrom P, Heeney JL: Vaccine protection from CD4+ T-cell loss caused by simian immunodeficiency virus (SIV) mac25I is afforded by sequential immunization with three unrelated vaccine vectors encoding multiple SIV antigens. J Gen Virol 2004, 85:2915-2924.

4. Matsui M, Moriya O, Akatsuka T: Enhanced induction of hepatitis $C$ virus-specific cytotoxic $T$ lymphocytes and protective efficacy in mice by DNA vaccination followed by adenovirus boosting in combination with the interleukin- 12 expression plasmid. Vaccine 2003, 2 I: 1629-1639. 
5. Estcourt MJ, Ramsay AJ, Brooks A, Thomson SA, Medveckzy CJ, Ramshaw IA: Prime-boost immunization generates a high frequency, high-avidity CD8 (+) cytotoxic T lymphocyte population. Int Immunol 2002, I 4:3I-37.

6. Vuola JM, Keating S, Webster DP, Berthoud T, Dunachie S, Gilbert SC, Hill AV: Differential immunogenicity of various heterologous prime-boost vaccine regimens using DNA and viral vectors in healthy volunteers. J Immunol 2005, 174:449-455.

7. Garzon MR, Berraondo P, Crettaz J, Ochoa L, Vera M, Lasarte J], Vales A, Van Rooijen N, Ruiz J, Prieto J, et al.: Induction of gp I 20specific protective immune responses by genetic vaccination with linear polyethylenimine-plasmid complex. Vaccine 2005, 23: I384-I392.

8. Meseda CA, Elkins KL, Merchlinsky MJ, Weir JP: Prime-Boost Immunization with DNA and Modified Vaccinia Virus Ankara Vectors Expressing Herpes Simplex Virus-2 Glycoprotein D Elicits Greater Specific Antibody and Cytokine Responses than DNA Vaccine Alone. The Journal of Infectious Diseases 2002, 186: 1065-1073.

9. Timofeev AV, Kondrat'eva I, Karganova GG, Stephenson J: [Protective activity of a bacterial plasmid, bearing the gene for the tick-borne encephalitis virus NSI nonstructural protein]. Vopr Virusol 200I, 46:22-24.

10. Khoretonenko MV, Vorovitch MF, Zakharova LG, Pashvykina GV, Ovsyannikova NV, Stephenson JR, Timofeev AV, Altstein AD, Shneider AM: Vaccinia virus recombinant expressing gene of tickborne encephalitis virus non-structural NSI protein elicits protective activity in mice. Immunol Lett 2003, 90:16I-163.

11. Timofeev AV, Karganova GG: Tick-borne encephalitis vaccine: from past to future Moscow: Pronto Prints Ltd; 2003.

12. Phillpotts RJ, Stephenson JR, Porterfield JS: Antibody-dependent enhancement of tick-borne encephalitis virus infection. J Gen Virol 1985, 66:1831-1837.

13. Jacobs SC, Stephenson JR, Wilkinson GW: High-level expression of the tick-borne encephalitis virus NS I protein by using an adenovirus-based vector: protection elicited in a murine model. J Virol 1992, 66:2086-2095.

14. Rokitsky PF: Biological statistics. In Vysshaya shkola Minsk, USSR; 1964. (in Russian)

15. Schlesinger J], Drandriss MW, Walsh EE: Protection against yellow fever I7D encephalitis in mice by passive transfer of monoclonal antibodies to the non-structural glycoprotein gp48 and by active immunization with gp48. J Immunol 1985, 135:2805-2809.

16. Timofeev AV, Ozherelkov SV, Pronin AV, Deeva AV, Karganova GG, Elbert LB, Stephenson JR: Immunological basis for protection in a murine modelof tick-borne encephalitis by a recombinant adenovirus carrying the gene encoding the NSI non-structural protein. J Gen Virol 1998, 79:689-695.

17. Mackett M, Smith GL, Moss B: Vaccinia virus: a selectable eukaryotic cloning and expression vector. Proc Natl Acad Sci U S A 1982, 79:7415-7419.

18. Altstein AD, Andzhaparidze OG, Antonova TP, Baev AA, Baisar D, Bendukidze $K A$, et al:: Double recombinants of the vaccinia virus expressing hepatitis $B$ virus surface antigen and herpes simplex virus thymidine kinase. Dokl Akad Nauk SSSR 1986, 289: 1493-1496. (in Russian)

19. Chernos VI, Cheliapov NV, Antonova TP, Rakhilina LE, Unanov SS, Al'tshtein AD, Zakharova LG, Fodor II, Bendukidze KA, Komarov FI, et al:: Verification of the safety, inoculability, reactogenicity and antigenic properties of a live recombinant smallpox-hepatitis B vaccine in an experiment in volunteers. Vopr Virusol 1990, 35: 132-1355. (in Russian)

20. Altstein AD, Chernos VI: Poxvirus recombinants as potential vaccines. In Concepts in Virology Volume Chapter 35. Edited by: Mahy BWJ, Lvov DK. Switzerland, Harwood Academic Publisher; 1993:381-388

21. Buller RM, Smith GL, Cremer K, Notkins AL, Moss B: Decreased virulence of recombinant vaccinia virus expression vectors is associated with a thymidine kinase-negative phenotype. Nature 1985, 317:813-815.

22. Altstein AD, Zakharova LG, Loparev VN, Pashvykina GV, Gorodetsky SI, Chernos VI, Senkevich TG, Antonova TP, Andzhaparidze OG: Development of vaccinia virus recombinant on the basis LIVP strain inducing hepatitis B virus surface antigen. Dokl Akad Nauk SSSR 1985, 285:696-699. (in Russian)
23. Stephenson JR, Crooks AJ, Lee JM: The synthesis of immunogenic polypeptides encoded by tick-borne encephalitis virus. J Gen Virol 1987, 68: 1307-1316.
Publish with Bio Med Central and every scientist can read your work free of charge

"BioMed Central will be the most significant development for disseminating the results of biomedical research in our lifetime. "

Sir Paul Nurse, Cancer Research UK

Your research papers will be:

- available free of charge to the entire biomedical community

- peer reviewed and published immediately upon acceptance

- cited in PubMed and archived on PubMed Central

- yours - you keep the copyright

Submit your manuscript here:

http://www.biomedcentral.com/info/publishing_adv.asp
BiolMedcentral 